\title{
APPLICATION OF SYSTEM ARCHETYPES IN PRACTICE: AN UNDERUTILISED PATHWAY TO BETTER MANAGERIAL PERFORMANCE
}

\author{
Vladimír BUREŠ ${ }^{1}$, Fridrich RACZ ${ }^{2}$ \\ ${ }^{1}$ University of Hradec Králové, Rokitanského 62, 50003 Hradec Králové, Czech Republic \\ ${ }^{2}$ Vysoká škola manažmentu, Panónská cesta 17, 85104 Bratislava, Slovakia \\ E-mails: ${ }^{1}$ vladimir.bures@uhk.cz (corresponding author); ${ }^{2}$ fridrich.racz@gmail.com
}

Received 07 October 2015; accepted 15 June 2016

\begin{abstract}
Current dynamic business environment forces managers to apply various tools in order to improve organisational performance and effectiveness. System archetypes enable to cope with complexity and make appropriate decisions. This study is theoretically grounded in the field of economic cybernetics and system archetype analysis. It applies qualitative research on the sample of 54 managers with the high level of seniority. The aim is to reveal whether system archetypes are effectively used in practice. Two hypotheses focused on both knowledge about and application of system archetypes are tested. The results prove that there are inconsistencies tied to forms of system archetypes insight and knowledge. Moreover, there is an inadequate level of attention identified in investigated organisations. Results imply various potential research pathways that are outlined in the final section of the paper. Hence, the manuscript offers a unique insight into the current state of practical system archetypes utilisation and contributes to the explanation of the role of system archetypes in the economic cybernetics framework.
\end{abstract}

Keywords: business administration, economic cybernetics, explicit knowledge, qualitative research, system archetypes, systems thinking, tacit knowledge, top managers.

JEL Classification: M53, O15, D83.

\section{Introduction}

Till today, systems thinking has already been applied in various disciplines, ranging from construction (Rowlinson, Jia 2015) to education (Adham et al. 2015). The reason is quite obvious. Any system, no matter whether physical or social, has its own "physics". Understanding the physics is important if the system is to perform in a desirable way. Business administration is a specific environment, in which systems thinking principles have been applied for decades. The boom associated with the use of systems approach can be connected with the pioneering work of Peter Senge and the publication of his book called The Fifth Discipline (Senge 2006). Business organisations pertain to the group of social systems, which are characteristic with their complexity and softness (Bureš 2006a). Therefore, work of managers who struggle to model, design, and devel- 
op the organisational internal and external environments is not trivial, and any available tool or technique should be employed. For instance, particular models are constructed to create a knowledge base that could address different problems. Modelling has always been the core of organisational design and engineering. Models enable decision makers to separate the irrelevant complexities of the real world in pursuit of directing efforts toward the most important parts of the analysed system (Giaglis 2001). However, the use of these models is not always successful. The reason is the Conant-Ashby Theorem, which says that the results of a management process are determined by the quality of the model on which that process is based (Conant, Ashby 1981). Moreover, the law of requisite variety, defined by William Ross Ashby, and economic cybernetics, in a form of the Viable System Model by Stafford Beer (Beer 1995), play a significant role here. System archetypes represent one of the key concepts associated with application of systems thinking in social and/or economic systems. They possess the potential to significantly help with the aforementioned issue, since they represent a specific tool that might be used in the business environment in order to support analysis, planning, or decision-making. Although the system archetypes emphasise general issues hidden in dynamics of the system itself, they do not describe any problem specifically. Their main added value arises from the insights that they offer into the dynamic interaction in complex systems. This approach offers understanding of a particular system's structure and behaviour, which fosters communication and identification of high-leverage interventions for problematic complex system behaviour (Banson et al. 2016). As stated by Maani and Cavana (2007) or Nguyen and Bosch (2013), system archetypes provide a high-level map of dynamic processes that reveals the simplicity underlying the complexity of management issues. This also reveals different leverage points to overcome difficult challenges. Hence, system archetypes represent the main research construct of this study. The remainder of the paper is organised as follows. The next section briefly describes the theoretical context of modelling in business settings, with emphasis put on system archetypes. The second section presents the research methodology, whereas the third section depicts the acquired results, in which the relevant discussion is incorporated. Finally, the last section concludes the discussion.

\section{Modelling with system archetypes}

There are several modelling languages or techniques used in practice - e.g., Flowcharting, Unified Modelling Language Diagrams, Event Driven Process Chain, IDEF (family of "Integration Definition" techniques), Petri Nets, and Role Activity Diagram. All of them permit the use of functional and behavioural decomposition of the system, while the organisational and informational perspectives are only partly supported (List, Korherr 2006). Therefore, necessity to apply systems thinking has become an integral part of business administration. Systems thinking explores things as wholes and is highly relevant, because the world exhibits qualities of wholeness (Flood 1998). For the aforementioned reasons, the systems dynamics with its tools, diagrams, and techniques appeared during the second half of 1990s. The basic assumption underpinning the sys- 
tems dynamics paradigm is based on belief that although the real world exhibits a high degree of complexity, it is possible to capture this complexity in a model (RodriguezUlloa, Paucar-Caceres 2005). In the realm of systems dynamics, systems are modelled as closed-loop systems, which largely generate their dynamics internally. Models of complex systems that link qualitative reasoning and quantitative decision support have become increasingly necessary in the domain of business administration. System Theory offers two major strategies for dealing with the challenge of modelling complex systems adequately (Schwaninger 2003). While Ross Ashby's notion of essential variables remains out of scope of this manuscript, the concept of System Archetypes describes the repetitive common patterns that occur, for example, within the organisational behaviour (Prusty et al. 2014). They represent different types of dynamic patterns that recur. Schwaninger (2003) proposes that archetype-based modelling is a promising way to enhance the behavioural repertory of agents in organisations and society. It aids in achieving better models and, thus, in coping with complexity more effectively. System archetypes reveal a kind of simplicity underlying the dynamic complexity of managerial issues. Dynamic complexity may be understood in terms of a relatively small number of system archetypes. These explain each unique situation. One system archetype, or several interconnected system archetypes, may capture observable patterns of behaviour and explain why a complex of events occurs.

Historic reference behaviour and system structure archetypes represent key tools for creating rigorous system dynamics models. A causal loop diagram (CLD) represents the first-step in the process of modelling systems dynamics, which converts the complex elements into a simpler and more easily understandable structure. CLDs connect variables by key causal relationships with polarities to represent reality in order to display the behaviour of cause and effect from a system standpoint (Toole 2005). Modellers often delineate causal relationships by employing common archetypes of dynamic system structure. These produce behaviours, such as growth and decline, oscillation and complex combinations thereof (Bendor, Kaza 2012). Managers in all organisations face initially the same problem. Each organisation necessitates the effective management of the complexity of the environment in the area of its operation (Heaslip et al. 2012). Hence, system archetypes can be used in two different ways. First, more common use is for the purposes of system diagnostics. The main aim is to reveal and describe the existing structures within the organisation together with finding the answers to questions of what happened and what the cause was. In the business management area, system archetypes reveal the current structures and illustrate the rules of their functioning together with the emphasis on typical behaviours (Nguyen, Bosch 2013). Second, it is possible to model the future development of the situation. The forward time movement is employed, for example, in business administration for planning and decision-making. The archetypes serve especially as a fundamental frame for the outlined situations. The detailed modelling discussed further can be easily based on the archetypes. Nevertheless, it is necessary to add the indispensable values in order to appropriately complete the model as accurately as possible to the examined reality. 
Familiarity with system archetypes is a usable diagnostic tool for the identification of particular relations within the system. Moreover, these enable decoding of the basic structures from which the discrete events and their behaviours are formed after a certain period of time. The specific applications are observed as complex problem solving in healthcare (Bureš et al. 2012; Wong et al. 2012), education (Galbraith 1998), or intellectual property management (Spivey et al. 2011). Some studies are focused on the description of a particular archetype and its characteristics. For instance, Guadalupe and Beruvides (2012) offer the methodology for the identification of the Tragedy of the Commons archetype. Furthermore, some archetypes are generic (these represent the main focus of this manuscript) and, thus, more or less independent in terms of application domain. On the other hand, there are studies focused on system archetypes closely tied to a specific domain. For instance, Ariya and Chakpitak (2016) deal with system archetypes specific for the supplier relationship management, or Guo et al. (2015) apply system archetypes to construction of safety management. They identify eight archetypes, ranging from "workers' conflict goals" to "blame on workers" or "reactive and proactive learning”. There is no doubt that both types of system archetypes are powerful tools, enabling the revealing of the undeserved consequences (Prusty et al. 2014). Nevertheless, although the system archetypes have already been applied as a main tool in research studies, the very low number of studies has been published in the scientific resources indexed and abstracted in prestigious databases, like Scopus or Web of Science. For instance, only 25 records are available in the Scopus database associated with papers with the keyword "system archetype" and published in 2014, 2015, or 2016. Additionally, only 13 records are included in the subject area of Business, Management, and Accounting (to the date of March 10, 2016). With such significance of system archetypes proclaimed in existing studies and so insufficient number of records in scientific databases, one has to ask the following question: "When system archetypes are considered as a meaningful and useful tool for business administration, to what extent do top-managers know and use them in their practice?" A similar research question has not been answered yet, and related studies published so far offer only fragmented or incomplete information (Kolerová et al. 2014).

\section{Methodology}

The answer of the research question was grounded in the study, with theoretical starting point based on the work of Senge (2006). He documented the most common set of patterns of behaviour in organisations that have the tendency of reoccurring. Each system archetype has its own specific causal storyline. This storyline is universal and can be applied to the understanding of individual manifestations inside organisations. For instance, the "Fixes that fail" archetype has the "creaky wheel" as its main storyline. In this archetype, a quick fix is applied to a pain point (or "creaky wheel") to reduce its symptom and the "noise" generated by it. The storyline gets complicated when the unintended effects of the quick fix become consequential. These effects start to add to the problem symptoms making the quick fix less or totally ineffective. All system 
archetypes have a structure. This structure consists of a number of mostly endogenous variables and one or more feedback loops. Quite often, there is a delay embedded in the feedback loop that usually contributes to the unintended consequences of the behavioural pattern. Endogenous variables are those that form part of the feedback loops that both modify and are modified by other variables. Up to now, various system archetypes have been identified; for instance, Kim (2000) describes and provides examples of eight archetypes. Nevertheless, ten basic system archetypes are usually discussed (Urze, Abreu 2014). The essential archetypes used in this study are the following:

1. Limits to Growth;

2. Shifting the Burden;

3. Eroding Goals;

4. Escalation;

5. Success to the Successful;

6. Tragedy of the Commons;

7. Fixes that Fail;

8. Growth and Underinvestment;

9. Accidental Enemies;

10. The Attractiveness Principle.

From the methodological perspective, the conducted research followed guidelines described by Noble and Smith (2015). The research was qualitative in nature, because data, mostly in a form of opinions or insights, was collected and interpreted. However, some quantitative data was also gathered for the purposes of reliability and validity (Kuper et al. 2008). Two working hypotheses were formulated:

H1: Managers at the high levels of seniority possess knowledge about system archetypes, predominantly in a form of tacit knowledge.

H2: Less than $50 \%$ of organisations deal with system archetypes explicitly.

For the purposes of this study, the self-administered structured questionnaire was employed. The respondents were chosen from middle and top managers of large organisations in the Czech Republic. Their selection followed the judgemental technique, snowball technique, and criteria-based technique (Patton 1990). Eventually, answers from 54 respondents were acquired and consequently analysed. Respondents working in international and multinational organisations, directors, members of top management, or private business owners were included in the study.

The questionnaire included 13 questions, and various scales were applied (including dichotomy answers, open answer, ten-point scale, etc.). The order of the questions was not linear. Short Guide (an introduction to system archetypes) represented the supportive part of the questionnaire. This guide could have been used by respondents in association with selected questions (see Fig. 1). Figure 1 illustrates the flow chart of included questions. 


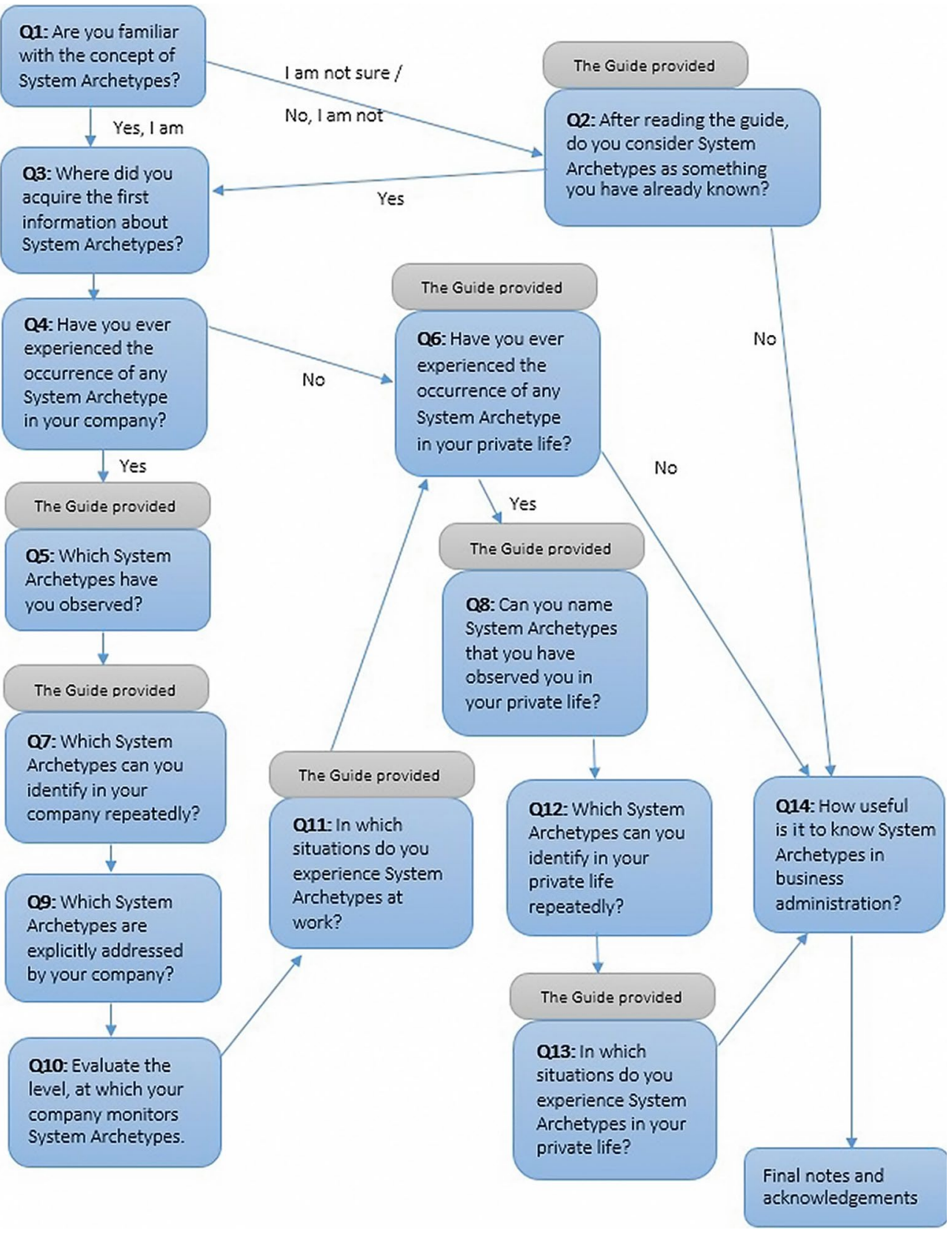

Fig. 1. The flow chart of questions 


\section{Results}

This section discusses the results based on the respondents' answers. Two main hypotheses are addressed and discussed.

\subsection{Insufficient knowledge of the system archetypes}

The first hypothesis states that managers at the high levels of seniority possess knowledge about system archetypes, predominantly in a form of tacit knowledge - in comparison to explicit or implicit knowledge, as differentiated by Bureš (2006b). The research revealed that only $22 \%$ of respondents do know the term "system archetypes" and are aware of their importance in the business administration realm (see Fig. 2). Thus, explicit or implicit knowledge of the concept can be assigned only to a minority of respondents. In the case of these managers, their higher ability to manage knowledge and increased use of their potential can be assumed. From the perspective of economic cybernetics, the variety is large enough to overcome certain limitations emphasised by the Law of Requisite Variety (Espejo, Dominici 2016). This law states that a "controller" has requisite variety. In this case, managers who have to perform managerial functions, such as planning, controlling, decision-making, or organising, represent controllers. The law claims that managers have limited capacity to maintain the outcomes of a situation within a target set of desirable states. This implies that knowledge of system archetypes can improve the managerial process, due to better alignment of mental models with reality (Scott et al. 2016). On the other hand, 78\% of respondents have not heard this term at all or are not able to link it with business administration. Therefore, these respondents had a chance to read the Guide and answer the questions again. Surprisingly, the vast majority of them (except for one) stated that after reading the guide, they consider System Archetypes as something they already know. This finding indicates that systems archetypes mostly represent tacit knowledge that is shared within the organisations with the help of specific tools and in specific directions (Zhang, He 2016). This fact can be considered as one potential research path that might be explored in future research projects.

Moreover, respondents realised that they have already experienced archetypal situations (see Fig. 3). Figure 3 orders archetypes according to the list stated in the second section of this paper. This question was multiple choice with more possible answers. Therefore, the frequency count does not correspond to the number of respondents. Consequently, all respondents were able to identify the existence of all system archetypes at their work, regardless of the frequency of their occurrence. Limits to Growth (1), Shifting the Burden (2), and Tragedy of the Commons (6) represent system archetypes that appear at work the most frequently. The same archetypes were identified as those that appear repeatedly within the companies. This relationship between single occurrence and repeated occurrence is confirmed by the correlation coefficient with the value of $\mathrm{R}=$ 0.993. Not surprisingly, only the Fixes that Fail (7) archetype appears rather repeatedly than on a one-time basis. This particular archetype is studied in the managerial literature with applications to automotive industry (Soo et al. 2015), tourism (Mai, Smith 2015), or health care (Waldman 2007). 


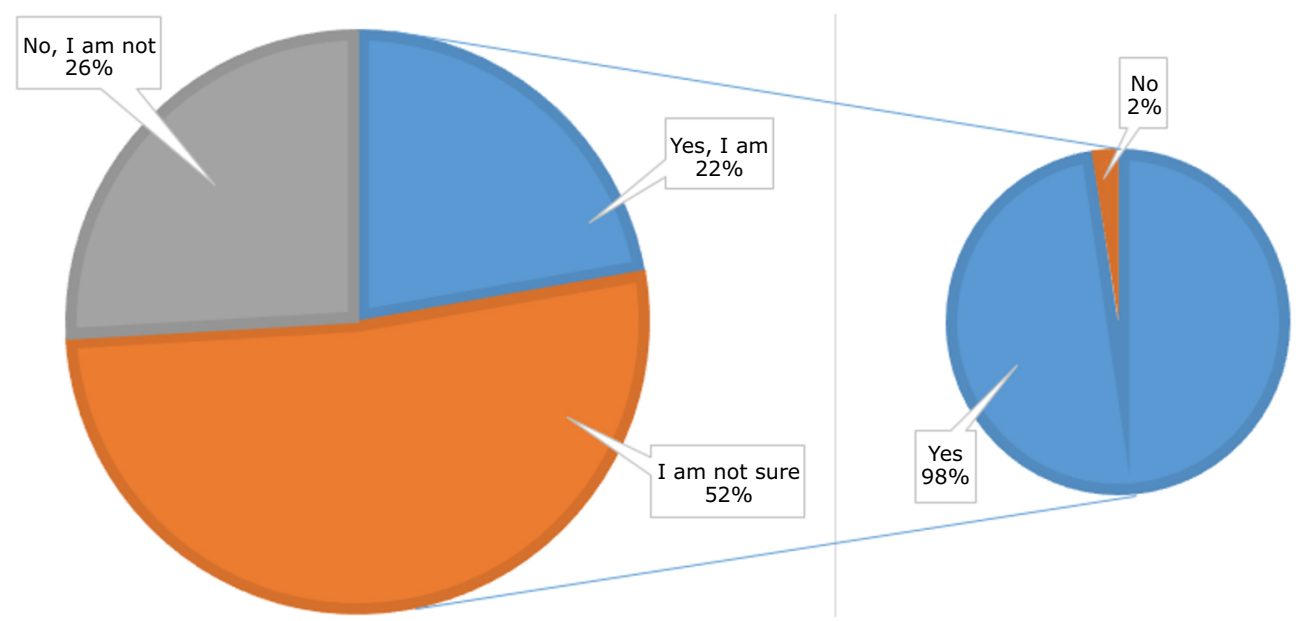

Fig. 2. Familiarity with the concept of system archetypes

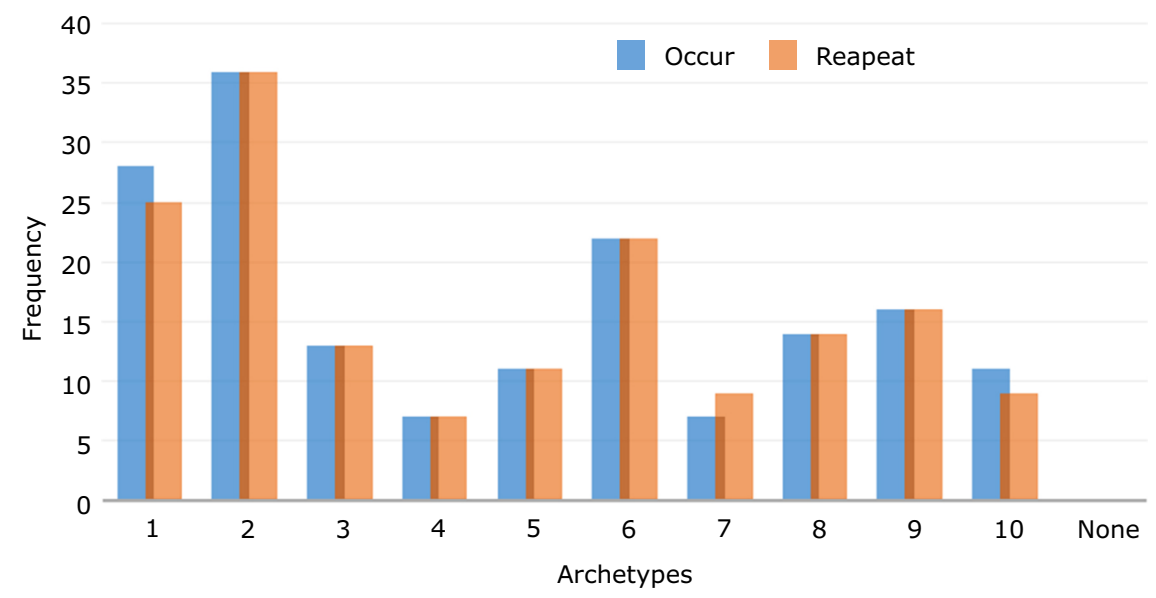

Fig. 3. Occurrence of system archetypes at work

Based on these findings, the first hypothesis is confirmed. Respondents were not mostly aware of the existence of system archetypes or any level of knowledge of them. Half of all respondents acquired knowledge of the existence of archetypal behaviour patterns only after reading the attached guide in the questionnaire. These managers did not know that these models were already discussed in the literature and that the archetypes could be classified into different types. Nevertheless, they were often familiar with the situations when archetypes occurred. Furthermore, they were able to correctly determine and describe them. Several examples of real-life situations and their association with specific system archetypes follow:

- Too much translation work accepted by interpreters or projects assigned by single project managers (Limits to Growth),

- Solving symptoms rather than issues, due to various reasons (Shifting the Burden), 
- Level of seniority that influences results, outcomes, and consequent evaluation of these (Success to Successful),

- Insufficient internal communication (Accidental Enemies),

- Unwillingness to invest any kind of input (energy, time, finance) in order to develop the business (Growth and Underinvestment).

The acquired feedback confirms that systems thinking as a part of professional training and seminars is very poorly presented. Aminu and Mahmood (2016) empirically evidenced that tacit knowledge significantly influences the integration and development of explicit knowledge and proved influence of both on organisational performance. Hence, it might be concluded that explication of System Archetypes can positively influence the organisational development in the future. However, this relationship needs to be proven further, based on a study with appropriate dataset.

\subsection{Value of system archetypes at the organisational level}

The second hypothesis states that organisations dealing with system archetypes explicitly are in the minority. It might be anticipated that the results of this hypothesis verification might be closely related to the results associated with the first hypothesis, because respondents are in charge of developing and managing an organisational unit, which was analysed. However, to avoid any bias that could have influenced the findings, this fact was explicitly stated, and the investigator triangulation took place.

Acquired results reveal that in the majority, particular companies address none of the archetypes (see Fig. 4). Only the Growth and Underinvestment (8) archetype is more or less monitored, very likely due to its link to financial aspects of business (Duggan 2009). However, other reasons trigger monitoring of this archetype. For instance, Mirchi et al. (2014) found that global population and economic growth, coupled with the inadequate investment in the ecological systems maintenance, threaten to degrade environmental integrity and ecosystem services that support the global socioeconomic system, indicative of a system governed by the Growth and Underinvestment (G\&U) archetype.

Limits to Growth (1), Shifting the Burden (2), and Eroding Goals (3) represent system archetypes that are officially addressed only occasionally. Further, the Attractiveness Principle (10) is not mentioned at all. This principle is used for predictions (Duncan 2007) or dynamics modelling (Swanson, Gleave 2008). Therefore, its inclusion might positively influence companies' performance and the market value.

When the level of monitoring and usefulness of particular system archetypes is considered, respondents provide answers with opposite tendencies. Where they found the archetypes Tragedy of the Commons (6), Fixes that Fail (7), and Growth and Underinvestment (8) as the most useful, their organisations monitor mostly archetypes Limits to Growth (1), Shifting the Burden (2), and Eroding Goals (3). This fact is apparent in Figure 5, in which 10-point scale was used: from (1) Nothing at all, to (10) Very carefully in case of monitoring, and from (1) Completely useless to (10) Absolutely useful in case of level of usefulness. This result corresponds with the previous sub-question presented in the paragraph above. 


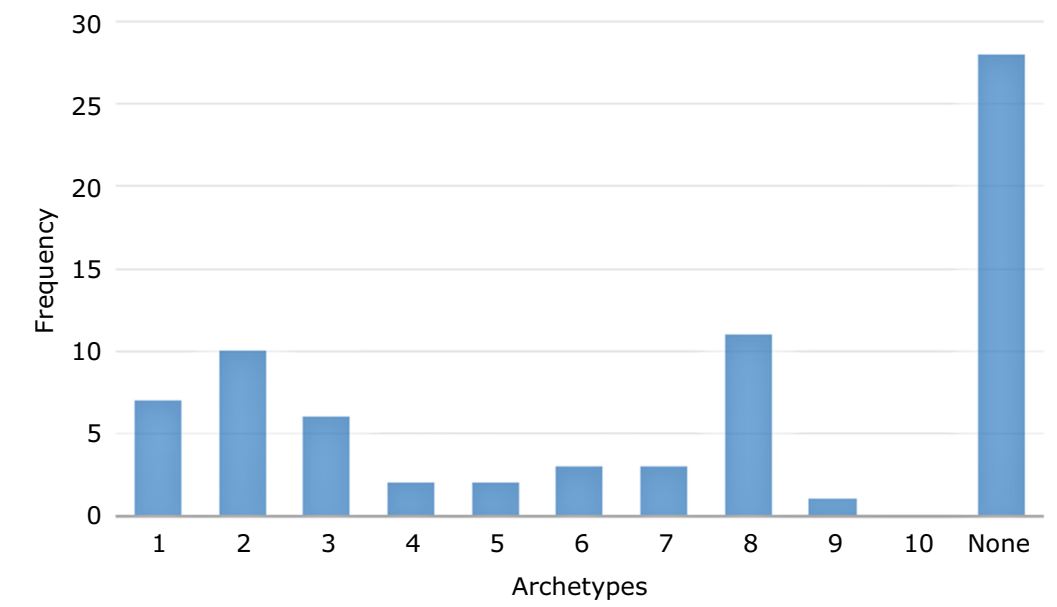

Fig. 4. Addressed system archetypes

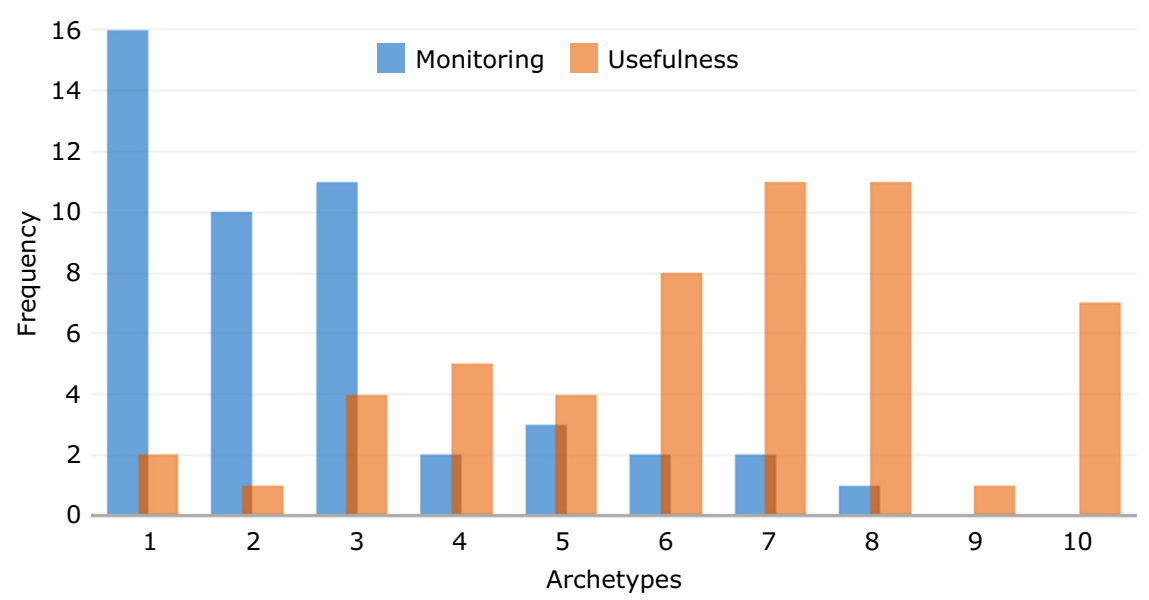

Fig. 5. Level of monitoring and usefulness

The second hypothesis is confirmed, because acquired results prove that companies mostly do not deal with system archetypes. Although system archetypes are considered to be useful (modus is equal to points 7 and 8 on the 10-point scale, median is equal to point 7 on the same scale), few of them are really monitored or officially addressed. It is difficult to lose the impression that archetypes possess the potential to reveal the imperfections of already-used solutions that are promoted on the basis of mental models. The archetypes reveal worse human characteristics. Therefore, it will take time till they are perceived as a major area for improvements within all companies. This corresponds with the fact that archetypal behaviour in the organisational environment is not monitored and tackled at the official level. Another reason why changes in acceptance and implementation of a new system of trends will last for a particular period of time lies in the complexity of necessary changes. This surely represents one of the main barriers to 
the overall transformation. The learning organisation is linked with the preparedness to learn and improve continually. The persistence and openness to new incentives and the ability to implement them belong to the most crucial characteristics of current managers who aim to work on the continual improvement of their organisations. System archetypes might be the first step to the implementation of learning the organisation concept.

Going back to the Viable System Model and the economic cybernetics point of view, this study revealed that organisations fail at the Systems 3, 4, and 5 in the model (Beer 1984). To be more specific, productivity, latency, and performance as metrics defined at the model's System 4 suffer from insufficient knowledge of system archetypes. Then, missing or incomplete algedonic alerts can be considered as negative consequences. However, the current situation might be improved with the help of various approaches. For instance, training agencies can aim to prepare attractive and useful training courses for employees at managerial positions, because the topic of system archetypes possess a significant potential to be included and offered. A lot of managers have already heard about system archetypes. Nevertheless, they can hardly realise their employment in practice. This causes their weak utilisation. Most of the managers consider the knowledge about system archetypes as significantly important. Therefore, it might be assumed that their attention will move to the seminars dealing with these issues. Furthermore, self-studies of professional literature appear as a weak source for information retrieval of new trends in management. This situation prevails, even though a lot of quality publications about management are available, and most of them also discuss the systems thinking. Moreover, some of them are based on the idea of systems thinking as a fundamental principle and consider it as a standard approach.

Although this study evidences that system archetypes do not represent anything unnatural to most people, non-linear thinking is quite difficult for all of them (Hamid 2009). Various tools, such as systems dynamics modelling software packages, have already been created in order to help managers to capture complexity and non-linearity. However, their utilisation might also lead to different perceptions of behaviour, which, as a consequence, can doubt the responsibility and competence (Bureš 2015). Positive news is that the latest development tries to improve the functionality and, for instance, include the algorithmic detection of archetypal structures (Schoenenberger et al. 2015). If an organisation does not only want to survive in the current world for a few years but also would like to build stable as well as successful structure, it will have to understand, use, and improve systems thinking and its particular implications. Understanding and employment of system archetypes might be the first step in this learning process. Each responsible manager is concurrently the crucial decision-maker influencing further development of his/her organisation. It is generally accepted that his/her self-development and commitment to the work quality in an organisation might influence the performance of the whole team. However, systems thinking furthers the mentioned issues and opens new perspectives of the organisational future. Due to the appropriate use of system tools, it enables ensurance of the continual growth and efficient utilisation of its own options. 


\section{Conclusions}

System archetypes reveal hidden behavioural patterns and provide diverse perspectives on common issues. The difference lies in the application of circular rather than merely casual relationships, which leads to the perception of non-linear behaviour of a studied and analysed system. On the sample of 54 managers with the high level of seniority selected with the help of three specific sampling techniques, the presented study tested two hypotheses focused on the current state of application of system archetypes in organisations. First, it reveals that only a small percentage of employees with a high level of seniority knows about active system archetypes and related professional terminology, despite the fact that a certain part of respondents has acquired such information at universities. Second, findings demonstrate that nearly all respondents experience system archetypes within everyday tasks at work. The results also revealed that managers emphasise a significant knowledge of particular system archetypes. Nevertheless, the topic represented a totally new concept for most of them. Moreover, they do not use the archetypes in practice intentionally. In addition, hardly any organisation pays attention to system archetypes at all.

These results implies further research questions, which might be solved by both qualitative and quantitative research methods. Except the aforementioned focus on ways in which system archetypes are transferred in the form of tacit knowledge, mechanisms for transformation from the tacit to the explicit form or existence of other domainspecific archetypes can be investigated. The following might serve as examples of potential research topics - why managers are not informed sufficiently, why they do not employ available tools to a wider extent, why professional trainings do not include system archetypes, why the same archetypes are repeatedly experienced more often than others, or whether and how managers understand systems thinking, and whether they tend to transform their organisations into learning ones. These particular questions might as well as be elaborated in further and more detailed studies. However, these future research steps require formulation of different research questions, hypotheses, and proper methods. Simultaneously, the research should be conducted in more types of organisations as well as in more countries in pursuit to enhance the applicability of the results and recommendations. Furthermore, practical implications might be identified. For instance, the quantitative follow-up can focus on economic comparison of organisation explicitly, dealing with system archetypes and companies without any experience with this systemic concept. This would enable managers to conscientiously consider, whether they need to explicitly deal with systems archetypes in their business units. In this way, the results contribute to development of application of economic cybernetics in practice and help to close the existing research gap dealing with association of the Viable System Model and system archetypes.

\section{Disclosure statement}

Authors hereby declare that no financial, professional, and personal interest or benefit arise from the direct applications of the research. 


\section{Acknowledgements}

The support of the FIM UHK Excellence Project "MAS Applications in Modeling of Complex Socioeconomic Systems and Intelligent Environments" is gratefully acknowledged. Authors would like to thank Mr. Petr Stránský for his help with data acquisition and processing.

\section{References}

Adham, K. A.; Kasimin, H.; Mat Isa, R.; Othman, F.; Ahmad, F. 2015. Developing a framework for a viable research university, Systemic Practice and Action Research 28(5): 503-525. http://dx.doi.org/10.1007/s11213-015-9341-8

Aminu, M. I.; Mahmood, R. 2016. On the relationship between procedural and declarative organizational memory and their effects on SME performance, International Business Management 10(3): 241-247. http://dx.doi.org/10.3923/ibm.2016.241.247

Ariya, P.; Chakpitak, N. 2016. Systems thinking in online travel agency of supplier relationship management, International Journal of Innovation and Learning 19(1): 63-84.

http://dx.doi.org/10.1504/IJIL.2016.073290

Banson, K. E.; Nguyen, N. C.; Bosch, O. J. H. 2016. Using system archetypes to identify drivers and barriers for sustainable agriculture in Africa: a case study in Ghana, Systems Research and Behavioral Science 33(1): 79-99. http://dx.doi.org/10.1002/sres.2300

Beer, S. 1984. The viable system model: its provenance, development, methodology and pathology, The Journal of the Operational Research Society 35(1): 7-25. http://dx.doi.org/10.2307/2581927

Beer, S. 1995. The heart of enterprise. New York: Wiley, 596 p.

Bendor, T. K.; Kaza, N. 2012. A theory of spatial system archetypes, System Dynamics Review 28(2): 109-130. http://dx.doi.org/10.1002/sdr.1470

Bureš, V.; Otčenášková, T.; Čech, P.; Antoš, K. 2012. A proposal for a computer-based framework of support for public health in the management of biological incidents: the Czech Republic experience, Perspectives in Public Health 132(6): 292-298.

http://dx.doi.org/10.1177/1757913912444260

Bureš, V. 2015. Comparative analysis of system dynamics software packages, International Review on Modelling and Simulations 8(2): 245-255. http://dx.doi.org/10.15866/iremos.v8i2.5401

Bureš, V. 2006a. Systems thinking as a basis for ambient intelligence, in 11th Annual SIGCSE Conference on Innovation and Technology in Computer Science Education, 26-28 June 2006, Bologna, Italy, 318.

Bureš, V. 2006b. Knowledge management and its implementation, in 2nd International Conference on Web Information Systems and Technologies, 11-13 April 2006, Setubal, Portugal, $115-118$.

Conant, R. C.; Ashby, W. R. 1981. Every good regulator of a system must be a model of that system, in R.C Conant (Ed.). Mechanisms of intelligence: Ashby's writings on cybernetics. Seaside: Intersystems Publications, 205-214.

Duggan, J. 2009. Growth and underinvestment: the impact of reactive capital acquisition strategies on market share, in 6th Conference of the European Social Simulation Association, 14-18 September 2009, United Kingdom, Code 110185.

Duncan, R. D. 2007. The olduvai theory: terminal decline imminent, The Social Contract 17(3): $141-151$. 
Espejo, R.; Dominici, G. 2016. Cybernetics of value cocreation for product development, Systems Research and Behavioral Science. http://dx.doi.org/10.1002/sres.2392

Flood, R. L. 1998. Fifth discipline: review and discussion, Systemic Practice and Action Research 11(3): 259-273. http://dx.doi.org/10.1023/A:1022948013380

Galbraith, P. L. 1998. System dynamics and university management, System Dynamics Review 14(1): 69-84.

Giaglis, G. M. 2001. A taxonomy of business process modelling and information systems modelling techniques, The International Journal of Flexible Manufacturing Systems 13(2): 209-228. http://dx.doi.org/10.1023/A:1011139719773

Guadalupe, L. J.; Beruvides, M. G. 2012. Tragedy of the commons: self-interest, at the expense of the system, in 33rd Annual International Conference of the American Society for Engineering Management 2012, 17-20 October 2012, Virginia Beach, VA, USA, 99-107.

Guo, B. H. W.; Yiu, T. W.; González, V.A. 2015. Identifying behaviour patterns of construction safety using system archetypes, Accident Analysis and Prevention 80: 125-141.

http://dx.doi.org/10.1016/j.aap.2015.04.008

Hamid, T. K. A. 2009. Thinking in circles about obesity: applying systems thinking to weight management. New York: Springer, 476 p. http://dx.doi.org/10.1007/978-0-387-09469-4

Heaslip, G.; Sharif, A. M.; Althonayan, A. 2012. Employing a systems-based perspective to the identification of inter-relationships within humanitarian logistics, International Journal of Production Economics 139(2): 377-392. http://dx.doi.org/10.1016/j.ijpe.2012.05.022

Kim, D. H. 2000. Systems archetypes I: diagnosing systemic issues and designing high-leverage interventions. Waltham, MA: Pegasus Communications, Inc. 29 p.

Kolerová, K.; Bureš, V.; Otčenášková, T. 2014. Usage of system archetypes in business administration by top-managers, in 23rd International Business Information Management Association Conference, 13-14 May 2014, Valencia, Spain, 1734-1743.

Kuper, A.; Lingard, L.; Levinson, W. 2008. Critically appraising qualitative research, BMJ 337: a1035. http://dx.doi.org/10.1136/bmj.a1035

List, B.; Korherr, B. 2006. An evaluation of conceptual business process modelling languages, SAC 2006, 23-27 April 2006, Dijon, France, 1532-1539.

Maani, K. E.; Cavana, R. Y. 2007. Systems thinking, system dynamics: managing change and complexity. $2^{\text {nd }}$ ed. Auckland, NZ: Prentice Hall.

Mai, T.; Smith, C. 2015. Addressing the threats to tourism sustainability using systems thinking: a case study of Cat Ba Island, Vietnam, Journal of Sustainable Tourism 23(10): 1504-1528.

http://dx.doi.org/10.1080/09669582.2015.1045514

Mirchi, A.; Watkins, D. W.; Huckins, C. J.; Madani, K.; Hjorth, P. 2014. Water resources management in a homogenizing world: averting the growth and underinvestment trajectory, Water Resources Research 50(9): 7515-7526. http://dx.doi.org/10.1002/2013WR015128

Nguyen, N. C.; Bosch, O. J. H. 2013. A systems thinking approach to identify leverage points for sustainability: a case study in the Cat Ba biosphere reserve, Vietnam, Systems Research and Behavioral Science 30(2): 104-115. http://dx.doi.org/10.1002/sres.2145

Noble, H.; Smith, J. 2015. Issues of validity and reliability in qualitative research, Evidence-Based Nursing 18(2): 34-35. http://dx.doi.org/10.1136/eb-2015-102054 
Patton, M. Q. 1990. Qualitative evaluation and research methods. London: Sage, 532 p.

Prusty, S. K.; Mohapatra, P. K. J.; Mukherjee, C. K. 2014. System archetype to understand unintended behaviour in Indian shrimp industry and to aid in strategy development, Systemic Practice and Action Research 27(4): 397-416. http://dx.doi.org/10.1007/s11213-013-9288-6

Rodriguez-Ulloa, R.; Paucar-Caceres, A. 2005. Soft system dynamics methodology (SSDM): combining soft systems methodology (SSM) and system dynamics (SD), Systemic Practice and Action Research 18(3): 303-334. http://dx.doi.org/10.1007/s11213-005-4816-7

Rowlinson, S.; Jia, Y. A. 2015. Construction accident causality: an institutional analysis of heat illness incidents on site, Safety Science 78: 179-189. http://dx.doi.org/10.1016/j.ssci.2015.04.021

Schoenenberger, L.; Schmid, A.; Schwaninger, M. 2015. Towards the algorithmic detection of archetypal structures in system dynamics, System Dynamics Review 31(1-2): 66-85.

http://dx.doi.org/10.1002/sdr.1526

Schwaninger, M. 2003. Modelling with archetypes: an effective approach to dealing with complexity, Lecture Notes in Computer Science 2809: 127-138.

http://dx.doi.org/10.1007/978-3-540-45210-2_13

Scott, R. J.; Cavana, R. Y.; Cameron, D. 2016. Mechanisms for understanding mental model change in group model building, Systems Research and Behavioral Science 33(1): 100-118. http://dx.doi.org/10.1002/sres.2303

Senge, P. M. 2006. The fifth discipline: the art \& practice of the learning organization. Revised \& Updated edition. New York: Doubleday. 445 p.

Soo, V. K.; Compston, P.; Doolan, M. 2015. Interaction between new car design and recycling impact on life cycle assessment, Procedia CIRP 29: 426-431.

http://dx.doi.org/10.1016/j.procir.2015.02.055

Spivey, W. A.; Gergely, M.; Munson, J. M.; Schreck, A. 2011. The promise of a global patent: insights from system archetype, in Technology Management in the Energy Smart World (PICMET), 31 July - 4 August 2011, Portland, OR, USA, Article number 6017740.

Swanson, J.; Gleave, S. D. 2008. Transport and the urban economy: the urban dynamic model, in REAL CORP 008, 19-21 May 2008, Vienna, Austria, 429-433.

Toole, T. M. 2005. A project management causal loop diagram, in 21st Annual ARCOM Conference, 7-9 September 2005, London, United Kingdom, Vol. 2, 763-72.

Urze, P.; Abreu, A. 2014. System thinking to understand networked innovation, in L. M. Camarinha-Matos; H. Afsarmanesh (Eds.). Collaborative systems for smart networked environments. Heidelberg: Springer. http://dx.doi.org/10.1007/978-3-662-44745-1

Waldman, J. D. 2007. Thinking systems need systems thinking, Systems Research and Behavioral Science 24(3): 271-284. http://dx.doi.org/10.1002/sres.828

Wong, H. J.; Morra, D.; Wu, R. C.; Caesar, M.; Abrams, H. 2012. Using system dynamics principles for conceptual modelling of publicly funded hospitals, Journal of the Operational Research Society 63(1): 79-88. http://dx.doi.org/10.1057/jors.2010.164

Zhang, L.; He, J. 2016. Critical factors affecting Tacit-knowledge sharing within the integrated project team, Journal of Management in Engineering 32(2): Article number 04015045 (in Press). http://dx.doi.org/10.1061/(ASCE)ME.1943-5479.0000402 
Vladimír BUREŠ was born in the Czech Republic in August 1977. He received his bachelor degree in Financial Management (1999), master degree in Information Management (2001), PhD in Information and Knowledge Management (2005) at the University of Hradec Králové, Czech Republic, and MBA in Global Management at the City University of Seattle, WA. He has already published five books (as author or as a member of the authoring team) and tens of scientific papers published in several journals or in conference proceedings. He has participated in both international and national research projects (e.g. $6^{\text {th }}$ or $7^{\text {th }}$ European Framework Program projects). In his research he focuses on systems engineering and system dynamics, knowledge management, and application of ICT in areas such as education, or business administration.

Fridrich RACZ was born in Slovakia in October 1968. He earned his master degree from System engineering at the Economic University in Bratislava, Slovakia in 1991. After short trial period in marketing he firmly set his professional career in Finance and Economics. After gaining experience in freshly evolving post-socialism Czech and Slovak market environment he joined Heineken corporation in Slovakia fulfilling the role of financial controller. By passing his first service year in Slovakia he joined a global Heineken Finance project in Heineken head-office in Amsterdam, NL. He spent more than 3 years in a global environment acting as a team leader in several European countries. Following his Finance and Controlling ambitions he then joined Heineken corporate Fi\&Co department working closely to the board. Upon his return to Slovakia he worked for several Slovak and Czech private equity companies, acting in different top-management roles. Currently he works for American real-estate corporation CBRE as the Head of Finance and Compliance for the Slovak entity. His PhD study focuses on system dynamics and knowledge management. 